\title{
Psychological and pedagogical support for children's and teenager's self-development and education globalization
}

\author{
Mariam R. Arpentieva \\ Department of Developmental \\ Psychology and Education, \\ K.E. Tsiolkovskiy Kaluga state \\ University \\ Kaluga, Russia, \\ $\underline{\text { mariam rav@mail.ru }}$
}

\author{
Tatiana Yu. Zalavina, \\ Department of Foreign \\ Languages in technical areas, \\ G.I. Nosov Magnitogorsk State \\ Technical University \\ Magnitogorsk, Russia \\ tania mgn@,rambler.ru
}

\author{
G.A. Stepanova \\ Department of Psychology and \\ Pedagogy, \\ Ugra state University \\ Khanty-Mansisk, Russia, \\ g stepanova53@mail.ru
}

\author{
Irina P. Krasnoschechenko \\ Department of Social and \\ Organizational Psychology \\ K.E. Tsiolkovskiy Kaluga state \\ University \\ Kaluga, Russia \\ kviip@yandex.ru
}

\author{
Margarita E. Kirichkova \\ Department of Social and \\ Organizational Psychology \\ K.E. Tsiolkovskiy Kaluga state \\ University, Professional \\ communications center \\ Kaluga, Moscow, Russia \\ margaritak05@mail.ru
}

\begin{abstract}
The article deals with the psychological and pedagogical support of children's and teenager's selfdevelopment in the context of solving the individual selfdevelopment problem, acting as one of the leaders in the context of the globalization of modern education. The article deals with the psychological and pedagogical support of children's and teenager's self-development in the context of solving the selfdevelopment problem of the individual. This context is one of the leaders in the context of the globalization tasks of modern education. The limits and frameworks (pedagogical resources) of the additional education of children and teenagers in the selfdevelopment of the individual and the realization of pedagogical ideas of Russian and world scientists are shown. The appeal to these limits and their investigation acquires particular relevance in globalization processes of education. Keywords - globalization of education, self-development, subjectivity, pedagogical support of self-development of the person, additional education of children, after-hour activity
\end{abstract}

\section{INTRODUCTION}

At the turn of the XX and XXI centuries in the world community a system-holistic view of man and the world, science and education arose. This view presupposes the solution of the global problems of humankind, including the problems of education as a practice of development of the individual and society. Global education is a complex idea that is taught to enhance people their understanding of the world. Students learning to be global citizens through global education will be able to learn more about the most significant issues of human life. These are the issues concerning international communities and migrations, problems of the corruption and social issues, problems of poverty, bioethical and biotechnological problems of mankind, problems of ecology and culture, science and arts, professional life and education, other global events, and international ideas in their typical classroom setting. Global Education will shape the way people understand themselves and the world to help better shape the world. This will facilitate initiatives and enhance learning in different communities, organizations and families, as well as around the world [1;2]. Global education that opens people's consciousness to the realities of the transnational and multi-religion interaction, multiregional and globalized world and awakens them in achieving a world of greater morality and spirituality, justice and equity, human duties and rights for all. Global education is understood to encompass development education, human rights and duties education, education for sustainable development, education for peace and conflict prevention and intercultural education; being the global dimension of education for citizenship and ecological harmony $[3 ; 4 ; 5]$.

\section{DISCUSSION}

Global education emphasizes the unity and interdependence of human society. It means the developing the sense of self and appreciation of cultural diversity, affirmation of social justice and moral, and human rights and duties, as well as building peace and actions for a sustainable future in different times and places, different nations and organizations.

Global education promotes constructive humankind values and assists students and teachers (educators) to take responsibility for their actions and to see themselves as global 
citizens who can contribute to a more peaceful, just, harmonious and sustainable world. Global Education is a dimension that runs through the total schools curriculums, an extra filter to help children and educators make sense of all the information about themselves and world and opinion the world is throwing at them [6;7]. On methodology level, it combines some experiential and experimental (scientific) discussion based activities, a caring, co-operative and open outlook on the classroom and other types of human experience, and core concerns. It combines some experiential and experimental (scientific) discussion about culture and nature of the world, about all countries, regions and groups, about the causes of poverty and inequality (here as well as in other countries), criminality and corruption, about the technical and social environment and about life meaning problems and dimensions. Global Education is an active learning process based on the universal values of love and tolerance, solidarity and co-operation, equality and nonviolence, justice and moral, inclusion and participation, nobility and dignity. Global Education begins with raising awareness of global challenges such as poverty, unfair distribution of opportunities and resources, environmental degradation and climate change, violent conflict and nonrespect of human rights. It then creates a deeper understanding of the complex underlying issues [8;9]. Thereby it aims at changing people's attitudes and encourages them to reflect on their own role in the world. Global education motivates and empowers people to become active as responsible and active "global citizens" [10].

Global Education is a way of approaching and integrating different knowing and skills. It integrate everything we teach about the life and the world. It broadens understanding of the world and personal life horizons and encourages exploration of all subjects from a global perspective. It also contributes to the whole curriculum and enhances our understanding of the world. This education provides a comprehensive approach to educating for a just and sustainable future. It includes with religious and historical trends that have molded our understanding of "peace" and then presents a variety of ways to practice peace education in schools and communities, and explains how it can motivate students. The teaching and practice of peace, multicultural and other components of the global education provides a basis of valuable knowledge about resolving conflicts and transforming violence without the use of force, about life in harmony with nature and culture, social and personal essences.

Unfortunately, in Russia global education is a topic not disclosed. A number of similar approaches are devoted to its comprehension, including the research of scientists and practitioners in the field of studies of the evolution of humankind $[11 ; 12 ; 13 ; 14]$. Among them, we can especially highlight the works of cosmopolitan philosophers, who comprehend the co-evolution of man and nature, the role of space in this evolution $[15 ; 16 ; 17 ; 18]$. We can also single out the work of economists who consider the relationship and role of social, human and cultural capital in the development of production technologies on different turns and within the framework of different models of socio-political and economic development $[19 ; 20 ; 21]$.

The solution of global problems of the present, ensuring the sustainable development of humankind as a planetary phenomenon, a prosperous future of society assumes the "cosmization" of human consciousness and the concerted actions of the world's population to harmonize relations in the system "man-society-nature" [22, p. 335]. Globalization today is one of the main factors of civilizational development and of civilizational regress. The process of globalization is interpreted as the formation of a single interconnected world, the process of the unification of humankind on a worldwide scale [21]. It is a process of unification, universalization of consciousness and being of people. It is inevitably associated not only with development, but also with the destruction of culture, including the culture of education. Without special effort and understanding of the purpose of globalization, it becomes primitive. The goal is to achieve a new level of consciousness of people, improvement in General. Humanity must recognize itself as a cosmic reality, as a subject whose actions affect itself, on Earth and in space. It is important for humanity to understand why it strives into space and why people need to unite. They need to unite and go into space not for the sake of sustainable production and common wellbeing, but for self-realization and self-fulfilment.

The processes of globalization, unfolding in our time, fundamentally differ from their historical precedents. They embrace the person, society and nature in their multifaceted interrelations, manifest not only in vast territories, but on the whole of our planet, in all countries of the world and touch upon vital interests, the future of every inhabitant of the Earth [14].

In turn, the modern paradigm of education should reflect the cardinal changes in the character of human development of the beginning of the modern century. The modern paradigm, concepts and technologies of education should be aimed at the formation and development of a personality capable of meeting the challenges of situation. According to the researchers, education is in the epicenter of globalization. The scientists note that it is here that a new generation is being formed, on which the real implementation will depend, both the positive aspects of globalization and the elimination of its negative consequences. Therefore, it is in the sphere of education that one must carefully study the phenomenon of globalization, its driving forces, its consequences, and influence these processes. Education in the modern world becomes an integrating factor and a condition for the development of the individual and the entire world community (there is satisfaction of both individual and social needs) [17].

UNESCO and the Council of Europe at the beginning of the XXI century, the concept of global education was formulated: "The Earth is our common home". The main tasks of which are the formation of an understanding of the world on the basis of holistic (perception of the world as a whole) and humanistic views; education of the person responsible for all forms of life on Earth and in the cosmos; education of a person who is able to combine freedom of choice with 
personal responsibility for the decisions made, universal human interests with national ones, security in the world with tolerance, friendship among nations, etc. [10, p. 108]. Proceeding from UNESCO documents, the main goal of the XXI century education is a full-fledged, qualitative development of the person; one of the main tasks is the formation and development of a global (cosmic) understanding of the world and self in this world.

The modern development of the world community requires an innovative education that would form a person's ability to foresight the future and responsibility for it. One of the main objectives of the XXI century education should be to disclose the universal interdependence, the integrity of all existing on the Earth and in the Universe, the discovery of the mechanism of development of this relationship, the definition of a special role and responsibility of man for preserving this integrity and himself in it.

The idea of the formation and development of the "personal" global responsibility makes it necessary to orient the modern educational process on preparing students for solving global problems, for spiritual and scientific development of the surrounding world. The idea of the formation and development of the "personal" global responsibility makes it necessary to orient the modern educational process for the upbringing of moral qualities that meet the imperatives of survival and development, and the imperatives of the sustainable development of human civilization and personal self-realization [18]. In turn, the formation of global responsibility is an integral component of the process of selfdevelopment of the individual, assuming, on the one hand, freedom of choice. On the other hand, responsibility for its implementation. Turning to the definition of freedom, we emphasizes that it is not limited to the choice of external alternatives, on the contrary, personal freedom is an existential quality of the individual, the ability to internal choice. Another important aspect of determining freedom is the responsibility for personal and group choice. When a person or group, when the humankind chooses himself, they learns to take responsibility and keep an answer not only to others (such a responsibility is of a formal nature), but also to himself, to his conscience and morality [19]. Existential responsibility is the management of freedom as exits beyond the limits of social existence, which should be directed to the benefit of the person himself and surrounding people, of humanity as a whole. It should be noted that the idea of educating global responsibility was anticipated by many philosophers, culturologists, sociologists and psychologists, including Russian cosmists (V.I. Vernadskiy, N.G. Kholodniy, K.E. Tsiolkovskiy, A.L. Chizhevskiy, V.S. Soloviev, N.A. Berdyaev, N.K.and E.I. Roerich, N.F. Fedorov, A. von Humboldt, K.S. Lewis, P. T. de Chardin, A. Bergson, E. Le Roy, A. Whitehead, S. Alexander, L. Clages, C. du Prel, R. Beck, S. Grof, K.N. Ventzel, A. Ghosh and others cosmists). The archetype of unity is the most important for cosmism. Cosmism is a holistic view for which the principle of integrity is the basis for solving all major problems. It is no coincidence that already in ancient times cosmism acted as a teaching about the unity of microcosm and macrocosm, the essence of which is that man is not just a part of the cosmic whole, but such a part, which in a compressed form expresses this whole, i.e. the nature of man contains in miniature the entire cosmos. Cosmism is a kind of protest, a revolt against the limiting and compressing framework of everyday life, against mortality and human limbs. Cosmism is the search for ways of immortality both for an individual and for humanity as a whole, and at the same time a special ontological status of life and human consciousness, their relationship to eternity and to the soul. Cosmism will affirm the multidimensional and multilayered nature of the existence of both the universe and man. He opposes "insular" (i.e. "island", self-contained) understanding of the past and internal (mental) life, allowing the possibility of their existence on different "plans" of being. At the same time, somehow a space is a necessary condition of immortality and infinity of life and consciousness.

In the context of the globalization of education, the following ideas of the space philosophy education are of particular relevance: comprehension of the infinity and diversity of the Universe embodied in the infinity of cognition of the Cosmos and man as its particles, ensuring the development of freedom of thought, personal freedom and existential responsibility for one's choice; the approval of the idea of the interdependence and continuity of man and the Cosmos, the realization of which ensures the integrity of the world-understanding and self-understanding, a holistic view of oneself and the world; the proclamation of the idea of moral Unity of man, humankind and the Universe, which predetermines the priority of moral values in the selfdevelopment of the individual and the search for ways of children and teenagers development in education; defining as the leading task of education the creation of conditions for making a person highly understanding and moral, and therefore more perfect and happy, capable of self-development and social implementation. This task can be embodied in the special content of "cosmic" education and in the special modern and classical educational methods, technologies, concepts and methodologies used [13].

One of the main feature of cosmism is not in the contemplative, passive position of man to the Earth and the Universe, but in the formation of his active position. Man is in active dialogue with the world. It was within the framework of cosmism at the beginning of the $\mathrm{XX}$ century that an understanding of the responsibility of the consciousness's for resolving the contradictions between man and mankind, man and nature was born. Man is a creator and donator, not only a consumer and destroyer. Therefore, cosmists have always affirmed the priority of moral education and culture interpersonal and intergroup relations. Perfection and selfdevelopment of man, in the opinion of Russian space scientists, is the main task of human sciences.

The objectives of education, reflecting the axiological ideas of cosmism, can be formulated as follows: child and youth education as a citizen of the universe; The result should be a person's awareness of the unity of his life with the life of the cosmos; child and youth education as a free creative person 
(development of individuality, personal self-awareness); the result should be an individual's awareness of the meaning of his life in connection with the meaning of the existence of mankind and the world; child and youth education as a member of society (development of social consciousness) and as part of the natural community; the result is a person's realization of his unity with humanity as a collection of individuals rising to higher forms of harmonic existence, and unity with the life of the Planet [16, p. 67].

The main aim of the modern educational system should be the formation and development of a new outlook for children and teachers. This is unity and cosmic outlook, it stimulate the emergence of new meaningful landmarks as a result of comprehension by each person of the grandeur of its existence and purpose. The content of the educational process can be presented in the form of knowledge of the scientific and philosophical nature of the laws of the cosmos, the harmonious unity of man, humankind and the universe, the need to maintain and develop the original unity. Psychopedagogical ideas of cosmism found their actualization in the context of the theory and practice of the globalization of education. They can be presented in the context of educational practice for the implementation of psychological and pedagogical support for the self-development and social implementation of children and youth in the conditions of education. The definition of the category of psychological and pedagogical support for self-development is based on the theoretical constructions proposed in pedagogical psychology. The process of psychological and pedagogical support of children's and youth's self-development is an educational practice, involving the inclusion of an child, teenager and adult in the educational process with the goal of creating conditions for self-development, self-movement in the activities of all subjects of interaction [15]. According to V.I. Slobodchikov and E.I. Isaev, self-development is understood as the process of becoming "subjectness" in a given period. Self-development presupposes, on the one hand, personal freedom, on the other hand, responsibility before itself [23].

We believe that the greatest efficiency and effectiveness of psychological and pedagogical support for self-development of children of different age groups is achieved in conditions of additional education. This is because the environment (conditions) of additional education for children and teenagers have a number of important educational resources (opportunities): the priority in personal development belongs to "self-processes" (self-knowledge, self-development, selfactualization, self-improvement, self-forecasting). This priority is expressed in providing the child and teenagers with freedom of choice, taking into account the individual needs of the child or teenager and his family due to the variability and integrative character of complementary education. It manifests itself in the expansion and deepening of the educational space; the educational environment of the children's and teenager's association is favorable for the children to manifest their "I", self-expression in the circle of peers; children's and teenager's association is a favorable environment for the formation of the subjectivity of the child or teenager, in the equal dialogue between the teacher and the child, the co-existence of children, teenagers and adults is born; the absence of universal, uniform for all standards of the content of education and strict regulation of the educational process creates favorable conditions for creativity, initiative, success, selfknowledge and self-development; - in additional education there are conditions for the development of independence and individuality, responsibility and initiative of the child and teenagers. These conditions arise, among other things, thanks to the children's self-government, which presupposes the responsible execution of various social roles. In additional education there is a consideration of the pedagogical principle of the adoption and protection of the individual interests of the child. On the contrary, accounting for his academic merits is not the most important. The main thing - the creation of a teacher situation of success [12]. Psychological and pedagogical support of the child's and teenager's selfdevelopment in supplementary education is the creation of conditions conducive to the development of the subjectivity of children in the environment of a child-adult community. Psychological and pedagogical support of the child's selfdevelopment is organized in the form of a system of interaction accompanied and accompanying. As a result of interaction, the child learns ways of independent and optimal (subjectively) realization of personal choice on the basis of the system of value orientations formed, as well as resolving emerging problems that impede self-development [11].

The implementation of pedagogical support for the selfdevelopment of children in supplementary education should take into account the peculiarities of the situation of personal choice. The choice is based on the child's self-development. $\mathrm{He}$ creates conditions for self-determination. Psychological and pedagogical support takes into account the following features of personal elections:

- the formation of the child's (pupil's) ideas about the plurality of options (alternatives) for education and life. Additional education develops a system of pupil's representations by offering him a system of educational areas of self-realization;

- the formation of qualitative characteristics of the choice (the importance of choice, the assumption of responsibility for the choice, the experience of independent choice). Additional education develops the ability to choose by offering the student a system of educational areas of self-fulfillment, and also by creating conditions for the selection of children at different stages of development subjectivity (taking into account their age and other characteristics);

- the procedural aspect of the choice (assessment of the consequences of decision making and choice, the retention of the consequences of the choice, their correlation with the value system in the situation of "crossroads" in the moral choice, trying on probabilistic consequences). The procedural aspect of the choice is supported by an additional education through the development of the value-semantic sphere of the child, motivation for self-development through immersion in the content of additional education. Such education must be saturated with anthropo-cosmic ideas and existential values; 
- the determinants of choice (the existence of independence, freedom of choice, the realization of one's vital, moral position at the time of the choice). The determinants of choice are supported by additional education through the search and correction of technologies of psychological and pedagogical support for children's self-development in education;

- availability of readiness for selection (achievement of emotional satisfaction when making a choice, recognition of the decision as the best possible as a basis for self-acceptance, ability and willingness to accomplish independent elections and bear responsibility for them). Readiness for choice is supported by a teacher, a psychologist, a social worker by offering the child a system of educational areas of selfrealization in supplementary education. They create conditions for making a choice and responsibility for the choice for children who are at different stages of development of subjectivity (taking into account their age and other characteristics).

\section{RESULTS}

The embodiment of the psychopedagogical ideas of Russian space scientists in the context of psychological and pedagogical support for the self-development of children and teenagers is seen by scientists today in a number of aspects of the additional education:

- the use of forms of organization of classes that promote the development of personal freedom and the existential responsibility of children and teenagers (open group discussion, discussion in the form of a television talk show, mini-conferences, trainings, design classes on the declared educational interests of children, research, viewing and discussion of videos with identification actual problems, social design, etc.);

- Substantive emphasis of educational activities on the study of global and everyday problems;

- the priority of implementing integrated educational programs of different focus as a condition for ensuring the formation of a holistic view of themselves and the world around them,

- the orientation of education on the formation and development of the student's awareness of the cause and effect relationships of his and others' actions, the world as a whole. Such awareness creates a basis for the accomplishment of an independent choice, taking into account the study of possible scenarios for the development of events, the investigation of the consequences of certain elections and the activity to implement them. Awareness of the choice contributes to the formation of responsibility for the decisions made;

- development of children and teenagers by additional educational programs of aerospace orientation. The development of these programs contributes to the development of the child's and teenager's motivation for learning about himself and the Cosmos. The realization of its inseparable, involvement in the world around us, the Universe is combined with the formation and development of a truly scientific worldview.
The scientific worldview is based, in this context, on the tradition of Russian cosmism, the achievements of the aerospace industry, environmental science and global education. In addition, there is a development of a sense of patriotism and love for the Motherland, for the Earth. Development of cognitive abilities of children, expansion of their outlook, formation of not only visual-figurative (empirical), but also theoretical thinking develops. In the process of further education, students acquire competencies in the field of research (the ability to put forward hypotheses and find the means of their adequate study). In parallel, the experience of self-knowledge and self-forecasting accumulates. An important part of this experience - personal and creative achievements as the results of student selfrealization in additional education.

The content component of education can include the following aspects: providing extensive material for studying biographies of great people and help in understanding the concept of the Highest (the principle of having an ideal); formation and development of the idea of Man as the Microcosm, who came to Earth to fulfill his personal mission to free the planet and people from the captivity of death and ignorance; providing knowledge about Nature, about the laws of development and co-evolution of man and nature; creating conditions for the child to explore his personal potential and the capabilities of the "higher self", as well as studying ways of self-improvement; education of positive creative attitude to any kind of work, including educational, family, professional, understanding of the importance of meaningfulness and value fullness of labor; help in understanding the value of spiritual relationships and training in the norms of highly moral human relations; the formation of an integral picture of the world, and, consequently, of the rich inner world of man, of love for the external world, its beauty and harmony. As a result of the implementation of psychopedagogical support for the selfdevelopment of children in supplementary education, the educational resources of the educational environment of basic and additional education are updated. Many important moments of human life are being formed and are developing:

- children and teenagers are motivated to develop their subjectivity, their desire to know themselves and the world, to find their unique place in the world, develop criticality of thinking, overcoming of stereotypes, ability to display the individuality in different kinds of activity develops;

- there is a formation of a subjective position, one's own point of view, the ability to express one's opinion and defend one's position, to follow the principles of one's own;

- the idea of plurality of elections and freedom in decisionmaking is formed, the ability to see alternative ways to solve the problem is formed and come to an independent choice, the motivation and willingness to accomplish independent elections based on value orientations is formed;

- the perception of the world as an integrity (as a unified system) is formed, the level of awareness of the world and life, their cause-and-effect relations, increases. Psychological and pedagogical support helps to understand the relationship between the choice of a person and its consequences. Thanks 
to him, the children's and teenager's awareness of their involvement in the surrounding world, the country, the planet is actively formed;

- the children and teenagers form and develop responsibility for their own destiny, life of their relatives, the country, the planet, increased awareness of their actions, the results of their choice, predicting the consequences of their decisions and actions from the point of view of their influence on man, nature, the planet;

- there is a statement in the consciousnesses of children and teenagers of the priority of universal human, general cultural values, orientation is formed on humanistic principles in the exercise of independent choice.

- These results of additional or alternative education directly correlate with the tasks of global education. Global education is the development of global thinking, the upbringing of a sense of the involvement of children in the life of the planet Earth, our common home, the establishment of harmonious human relations with nature, with ourselves.

\section{CONCLUSION}

Thus, the central problem of globalization is the problem of transforming a person, further qualitative development, and transforming it into a more perfect being (in the spiritual, moral, strong-willed, intellectual, energy and somatic sense). This problem received a multifaceted development in the philosophy of cosmism, where it passed into pedagogical ideas. The pedagogues-cosmists not only set the task of educating a person capable of improving society on the principles of good and justice, but also regarded it as an integral part of the universal, whole cosmos. They proceeded from the organic unity of man, humanity and the universe. They represented man as a cosmic phenomenon, and they saw the process of formation and development of humankind as an integral part of the general evolutionary flow of cosmic life.

It can be concluded that the educational process, which in its goals, principles, content and technology relies on the global ideas of the philosophy of cosmism as a methodological basis, can provide an effective solution to the problem of the formation of the existential responsibility of the individual in the conditions of a globalizing world. Approaches to the organization of pedagogical support for the self-development of children can to find wide application in the educational practice of additional education and extracurricular activities in conditions of development Federal state educational standards. Pedagogical support for children's self-development in the conditions of education globalization is aimed to the global competency of the children. Global competency is defined in various ways, for example [24; 25; 26; 27]:

- Global competency is ability to define as Investigate the World, that is, to be aware of and interested in the world and its workings. This ability involves investigate and exploring globally significant questions and creating a coherent and complex response that considers multiple levels and perspectives and draws useful, defensible and creative conclusions.
- Global competency is ability to weigh perspectives (of the understanding and activity). Students recognize that they have a particular perspective of the understanding and activity and those others may or may not share it. They can then articulate and explain the perspectives of the understanding and activity of other people and can compare their perspective with others and construct a new understanding and ways of the action and life.

- Global competence entails effective and productive interaction and communication-both verbal and non-verbal with diverse audiences, opponents and proponents. Globally competent students are proficient different language. They are also skilled users of digital media and other modern technology.

- Global competency is ability to take action and participation. Globally competent students are able to weigh options based on evidence and insight, assess potential for impact, consider possible consequences, and act and reflect on those actions. Globally competent students are able to cooperate and serve to other individuals and organizations. "Global competency [is] the knowledge and skills that help people understand the flat world in which they live and the skills to integrate across disciplinary domains to comprehend global affairs and events and to create possibilities to address them. Global competencies are also the attitudinal and ethical dispositions that make it possible to interact peacefully, respectfully and productively with fellow human beings from diverse geographies." [28, p. 283]. In education, harmony of interests of a person, society, state and business is necessary. Global education is education aimed at the formation and development of a person as an individual, as an individual and a professional, as a partner and member of the community. It is aimed at actualization and realization of the essence of man, his abilities and purpose in a certain cultural, historical and socio-political environment $[29 ; 30 ; 31]$. The antithesis of the apocalypse as the peak of the crisis of mankind, focused on consumption and devoid of value, is apokatostasis as creative thinking that overcomes the crisis. Not a consumer appropriation, but creative mastering as a leading attitude towards the world brings humanity closer to the way out of modern crisis situations. The foundations of this type of thinking are formulated in the noosphere theory of V.I. Vernadskiy and other cosmists. On the ideological foundation of cosmism and concepts of the noosphere, renewal of education, emergence of innovative educational technologies, concepts, methodologies can be carried out $[32 ; 33]$. The purpose of man from the point of view of Russian cosmism is in his introduction into his home - the macrocosm. The purpose of man is to reveal his inner potential, to reveal and realize himself in accordance with individual possibilities and in relation to universal, world, universal processes. The essence of education is not so much in transferring the experience of the past to the pupil, but rather in expanding his own experience, providing both personal, and its general cultural growth. The pupil is formed in personal living of cultural, historical, natural-science, artistic and other educational processes and achievements. The teacher does not 
bring the student ready information, but accompanies him in an independent comprehension of the world, introduction into it. At the same time, his inner world is enriched by the external, the external is filled with the inner. In the infinite perspective, the inner and outer world of man merge together. The micro- and macrocosm are indistinguishable. "We must teach the child to feel at first a part of the small corner of nature accessible to him for encompassing the consciousness, part of the field, the forest, the meadow, gradually expanding that patch of land under which he perceives himself as one whole with nature, to the size of the earth as a planet, and from this already transition to the solar system, to the stellar system that makes up our universe, and to the boundless system of universes that encompass the entire boundless Cosmos [34, p. 162]. "Each person can grow to a consciousness that never leaves her, that she is not only the son of her closest parents, father and mother, but also the Son of the Great Cosmic Creator and the Great Creative Humanity. And the development in oneself of the feeling of this sonhood in relation to the Cosmos and Mankind is only a matter of time" [34, p. 163]. In order to raise the child's consciousness of the community of his life with the life of the Cosmos, it is necessary first to develop in his mind three ideas: the idea of the individual, the idea of society, ultimately encompassing all humankind, and the idea of the Cosmos. In other words, the child has to grow to the point of knowing that he is a creative person. Then he must grow to the point of remembering that he is a member of a certain creative society embracing humanity. And, in the end, he needs to understand that together with mankind he forms part of the creative Cosmos. "The goal of cosmic education is to bring the pupil to the consciousness of the community of his life with the life of the cosmic, to the consciousness that he, with the whole Cosmos, is one indivisible whole. This whole develops in some direction and that he wants it or not wants, one way or another takes part in this process of development of cosmic life" [34, p. 202; 35]. The conquests of science and technology should be directed only to the benefit of humankind, and not to contribute to improving the means of destroying people. The development of human consciousness, its spirituality, subjectivity and responsibility must begin from the early years of life under the guidance of experienced and spiritually-moral teachers endowed with the consciousness of the cosmoevolutionary role of man. K.E. Tsiolokskiy considered the most important value that a person has, his ability to moral self-development and self-transformation: man is as unlimited in development as the universe, and the conclusions of other cosmists similar to his views can be described as a moral system for the transfer of spiritual experience and knowledge. This system based on love for man as the main value, on the quest for a happy life for everyone on Earth and for an eternally continuing life in space. K.E. Tsiolokskiy and the conclusions of other cosmists similar to his views can be described as a moral system for the transfer of spiritual experience and knowledge [36; 37]. This system based on love for man as the main value, on the quest for a happy life for everyone on Earth and for an eternally continuing life in space. A person must face the Cosmos and seek a fusion with it. Such a person develops the feeling of the Cosmos, liberation from everything small limited, from "chains of invisible slavery". His soul is filled with freedom, infinitely wide creative love for life, for humanity. In the face of the Cosmos, a person is clearer than he ever realizes how unfeasible he is, to what extent he is possessed of all sorts of passions [34]. Therefore, giving oneself to these partial experiences and ideas, one must not forget about the integral single cosmic life and the life of Mankind as a whole.

\section{REFERENCES}

[1] D. Friesen, "Toward global horizons: Student stories' from an international teacher education project", in Action in Teacher Education, 1995, vol. 17(2), pp. 40-46.

[2] Cl.L. Gaudiani, "Global social development: Higher education's next moral commitment", in Educatiopal Record, 1995, vol. 76(1), pp. 6-13.

[3] D.E. Lo, "Implementing a global curriculum", in Gifted Education International, 1991, vol. 7, pp. 146-148.

[4] M.N. Milone, "Global education begins at home", in Technology \& Learning, 1995, vol. 16(3), pp. 48-50, vol. 52.

[5] S. Ostheimer, "Internationalize yourself and your classes, school, and community", in Business Education Forum, 1995, vol. 76(1) , pp. 44-47

[6] A.K. Sinha \& U. P. Sinha, "Some socialisational correlates of worldmindedness", in Asian Journal of Psychology and Education, 1997, vol. 2(3), pp. 27-30.

[7] J.A. Banks, "Multicultural Education: Issues and Perspectives". New York: Wiley, 2015, 360p.

[8] J.A. Banks, "Cultural Diversity and Education", London, New York: Routledge,2015, 366p.

[9] I.Harris, and M. Morrison, "Peace education". London: Jefferson, N.C.: McFarland, 2012, 292p.

[10] M. Bajaj, M. Hantzopoulos (Ed.), "Peace education: international perspectives". Bloomsbury: Bloomsbury Academic, 2016, 304p.

[11] O.A Urozhenko et al. (ed.), "Ideas of cosmism - pedagogy and education: the place of man on the path of evolution": materials of the scientific and pedagogical conference, March 14-15, 2008, Ekaterinburg. Ekaterinburg: A. M. Gorkiy Ural State University, 2009. 292p. (In Russian)

[12] K. H. Khairullin, “ Cosmism: life - man - the noosphere”. Kazan: Centre of innovative. technologies, 2015191 p. (In Russian)

[13] K. H. Khairullin, "The Philosophy of cosmism". Kazan : The printing House, 2003, 370p. (In Russian)

[14] N.M. Mamedov, "Globalization as a modern state of social development", in The era of global change. Moscow, 2004, pp. 34-36. (In Russian)

[15] V.G. Maralov "Fundamentals of self-knowledge and self-development: training Allowance". Moscow: Academy, 2004, 256p. (In Russian)

[16] N.A. Perekusikina "Value-goal priorities of Russian cosmism as the world outlook basis of the educational process", in Bulletin of the Buryat State University, 2013, vol. 1, pp. 64-68. (In Russian)

[17] E.A.Pushkareva, Yu.V. Pushkarev, O.A. Latukha, in "Russian education in the context of the innovative formation of the global organization of the socio-cultural space", in Problems of the logic of sociocultural evolution and the philosophy of Western Siberia. Biysk: BSPU them. V.M. Shukshin, 2007, pp. 404-405. (In Russian)

[18] I.M. Pushkin, "Formation of the global human responsibility in the light of the reforms of the national education", in Bulletin of the Northern (Arctic) Federal University. Series: Humanities and Social Sciences, 2012, vol. 1, pp. 141-145. (In Russian)

[19] K. R. Rogers, "A look at psychotherapy. The formation of man". Moscow: Progress, 1994. 480p. (In Russian)

[20] Z.I. Tyumasev (comp.), "Dictionary-reference book of modern general education”. St. Petersburg: Peter, 2004, 464p. (In Russian) 
[21] N.G. Tarasenko, "The value of K.N. Ventzel's cosmic pedagogy and M. Montessori's ideas about "Cosmic education" in resolving the problem of the formation of a person's world outlook", in Historical and SocioEducational Thought, 2011, vol. 5, pp. 116-121. (In Russian)

[22] N.G. Tarasenko, "The problem of the formation of an integral worldview of the individual in the context of ideas of the philosophy of cosmism", in Scientific Bulletin of Belgrad State University. Series: The humanities, 2011, vol. 6 (101), pp. 335-342. (In Russian)

[23] V.I. Slobodchikov, E.I. Isaev, "Psychology of human development", in . Development of subjective reality in ontogenesis. Moscow: SchoolPress, 2000. 324p. (In Russian)

[24] J.A. Mestenhauser, "Reflections on the past, present, and future of internationalizing higher education: Discovering opportunities to meet challenges". Minneapolis, MN: Global Programs and Strategy Alliance, University of Minnesota, 2011, 198p.

[25] A. Hamza, "International experience: An opportunity for professional development in higher education", in Journal of Studies in International Education, 2010, vol. 14(1), pp. 50-69.

[26] A. Russo, \& A. Sans, "Student communities and landscapes of creativity: How Venice "The World's most touristed city' is changing", in European Urban and Regional Studies, 2009, vol. 16(2), pp. 161175.

[27] F. Reimers, "Global Competency' Is Imperative for Global Success", in Chronicle of Higher Education, 2009, vol. 55(21), pp. A29.

[28] F. Reimers, "Educating for Global Competency", in Cohen J. \& Malin M. (Eds.), International perspectives on the goals of universal basic and secondary education. New York: Routledge Press, 2010, pp. 183-202.

[29] K. Gunesch, "Education for cosmopolitanism? Cosmopolitanism as a personal cultural identity model for and within international education", in Journal of Research in International Education, 2004, vol. 3(3), pp. 251-275.

[30] M.R. Arpentieva, O.N. Duvalina, I.V. Gorelova, "Intersubjective management in aerospace engineering", in Borikov V., Uchaikin S.,
Baranov P., Ivanova V., Dolgih A. and Ignatovskaya A. (Eds.) 5th International Forum for Young Scientists "Space Engineering" MATEC Web of Conferences. $12-14$ April 2017. Tomsk: National Instruments Russia Corporation, 2017, p. 01002. URL: https://www.matecconferences.org/articles/matecconf/abs/2017/16/matecconf_se2017 010 02/matecconf se2001002.html doi.org/10.1051/matecconf/201710201002 (accessed 10.02.2018)

[31] M.R. Arpentieva, "Innovative and traditional approaches to students' preparation for final attestation: the problem of learning styles", in Testing and language progress assessment: traditions and innovations. Bilingual collection of scientific articles and materials of the international conference. March 21-22, 2016, Surgut. Ed. by C. Westbrook, O. Simonova and A. Sitnikova. UK, Southampton, Russia, Surgut: Southampton Solent University, Surgut State University, 2016, pp. 5-11. (In Russian)

[32] A.P.Ogurtsov, L.V. Fesenkova (ed.) "Philosophy of Russian cosmism". Moscow.: New Millennium Fund, 1996. 402p. (In Russian)

[33] N.M. Efimova, "Ontology of Russian cosmism: (N. Fedorov, K. Tsiolkovsky, A. Platonov)".-- Kirov, Vyatka State Humanitarian University, 2006 96p.

[34] K.N. Venttsel. "Notes on space education". In: Venttsel K.N. Free education: Collection of selected works. Moscow: Association "Professional Education", 1993, 170p. (In Russian)

[35] A.V. Khutorskoy, "Pedagogy of Russian cosmism", in Private school, 1993, vol. 2, pp. 11-22. (In Russian)

[36] I.M. Pushkina, "Cosmic pedagogy as a historical and cultural phenomenon in Russia". - Moscow: RUDN, 2008, 282p. (In Russian)

[37] B.V. Emelyanov, "Cosmic landmarks of Russian pedagogy". In: Ideas of cosmism in pedagogy and modern education: Materials of scientificped. Conf., Ekaterinburg, 5-6 December. 2003. - Ekaterinburg: Publishing House of the Ural University, 2004,128p (In Russian) 